Working Paper

\title{
Workforce Issues in the Greater Boston Health Care Industry: Implications for Work and Family
}

\author{
Prepared by Mona Harrington, Ann Bookman, \\ Lotte Bailyn, and Thomas Kochan \\ With the assistance of Forrest Briscoe and Kate Kellogg \\ (All authors affiliated with the MIT Workplace Center) \\ \#WPC 0001
}

November 2001

For information regarding the MIT Workplace Center or for additional copies of this Working Paper, reference \#WPC0001 (see list on final page) please email workplacecenter@mit.edu, call (617) 253-7996 or visit our website: web.mit.edu/workplacecenter 


\section{TABLE OF CONTENTS}

\section{Executive Summary}

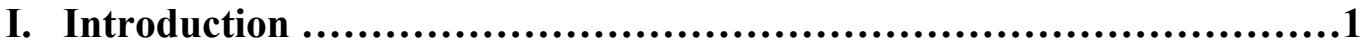

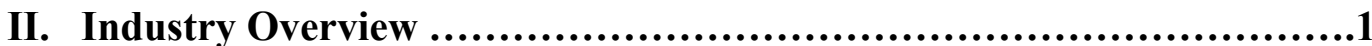

III. Key Workforce and Industry Performance Issues ......................2

IV. Implications for Connections Between Work and Family................6

V. Health Care Industry Response........................................9

VI. Next Steps: Leverage Points for Experimental Change....................12

VII. Next Steps: Continued Engagement...............................15

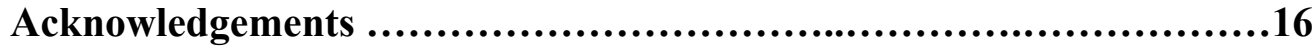

( Copyright 2002. Mona Harrington, Ann Bookman, Lotte Bailyn and Thomas Kochan. All rights reserved. This paper is for the reader's personal use only. This paper may not be quoted, reproduced, distributed, transmitted or retransmitted, performed, displayed, downloaded, or adapted in any medium for any purpose, including without limitation, teaching purposes, without the Author's express written permission. Permission requests should be directed to mona@mit.edu. 


\section{$\underline{\text { Executive Summary }}$}

Interviews with more than 40 leaders in the Boston area health care industry have identified a range of broadly-felt critical problems. This document synthesizes these problems and places them in the context of work and family issues implicit in the organization of health care workplaces. It concludes with questions about possible ways to address such issues.

The defining circumstance for the health care industry nationally as well as regionally at present is an extraordinary reorganization, not yet fully negotiated, in the provision and financing of health care. Hoped-for controls on increased costs of medical carespecifically the widespread replacement of indemnity insurance by market-based managed care and business models of operation--have fallen far short of their promise. Pressures to limit expenditures have produced dispiriting conditions for the entire healthcare workforce, from technicians and aides to nurses and physicians. Under such strains, relations between managers and workers providing care are uneasy, ranging from determined efforts to maintain respectful cooperation to adversarial negotiation.

Taken together, the interviews identify five key issues affecting a broad cross-section of occupational groups, albeit in different ways:

- $\quad$ Staffing shortages of various kinds throughout the health care workforce create problems for managers and workers and also for the quality of patient care.

- Long work hours and inflexible schedules place pressure on virtually every part of the healthcare workforce, including physicians.

- Degraded and unsupportive working conditions, often the result of workplace "deskilling" and "speed up," undercut previous modes of clinical practice.

- Lack of opportunities for training and advancement exacerbate workforce problems in an industry where occupational categories and terms of work are in a constant state of flux.

- Professional and employee voices are insufficiently heard in conditions of rapid institutional reorganization and consolidation.

Interviewees describe multiple impacts of these issues--on the operation of health care workplaces, on the well being of the health care workforce, and on the quality of patient care. Also apparent in the interviews, but not clearly named and defined, is the impact of these issues on the ability of workers to attend well to the needs of their families--and the reciprocal impact of workers' family tensions on workplace performance. In other words, the same things that affect patient care also affect families, and vice versa. Some workers describe feeling both guilty about raising their own family issues when their patients' needs are at stake, and resentful about the exploitation of these feelings by administrators making workplace policy.

The different institutions making up the health care system have responded to their most pressing issues with a variety of specific stratagems but few that address the complexities connecting relations between work and family. The MIT Workplace Center proposes a collaborative exploration of next steps to probe these complications and to identify possible locations within the health care system for workplace experimentation with outcomes benefiting all parties. 


\section{Introduction}

Over the past four months, researchers at the MIT Workplace Center have interviewed approximately 40 health care leaders in the Boston area. We conducted the interviews to gain an understanding of the most critical problems and challenges facing the health care industry from the perspective of the key stakeholders. This paper summarizes what we heard in those interviews. We have included, for the most part, what seem to be widely accepted understandings of the current situation and, when warranted, descriptions of conflicting points of view. We have not at this stage independently documented these observations, nor have we synthesized the extensive relevant literature.

Our next step is to bring the stakeholders together to both comment on whether we have captured their key concerns and to explore ways to address them that go beyond what individuals or separate organizations are already doing on their own. Throughout this process we will ask for thoughts and advice on the implications of the matters under discussion for the relations among work, family, and community in this region.

\section{Industry Overview}

The defining circumstance for the health care industry nationally as well as regionally at present is an extraordinary reorganization, not yet fully negotiated, in the provision and financing of health care generally. Scientific and technological advances in medical treatment, as well as empowered patients, have added both complexity and expense to the provision of care and have produced great change in the ways it is delivered. Simultaneously, both public and private financial structures for health care have been transformed in the past two decades by the widespread replacement of indemnity insurance by market-based managed care and business models of operation.

These new health care financing and delivery models promised cost control coupled with widely accessible preventive care and the improvement of overall quality through better incentives and administration. However, the reality of the new models has fallen far short of the promise, and the results are now under intense debate. In ten years of experience with managed care and hospital deregulation, Massachusetts has seen almost constant turmoil. The hope for differentiated delivery systems that would compete on quality and efficiency was lost as overlapping network models of managed 
care spread across the state and consumers refused to have their choices restricted. The struggle for market share among insurers, hospitals, and medical groups led to deep discounts and contracting struggles and put pressure on each organization's internal resources.

Within the health care delivery system, attempts were made to control costs.

These included: more restrictive review of tests, procedures, drugs, and referrals; shifting services from hospitals to outpatient clinics, extended care facilities, and home care; reducing hospital lengths of stay; applying business re-engineering models to nursing tasks; and shortening office visits. Belts have been tightened in all sectors of the industry--acute care and teaching hospitals, community hospitals, nursing homes, outpatient clinics, home care, and community services. However, after a few years of respite, costs are projected to resume their rapid rise in the current period.

We do not intend to address the overarching financial issues as such, as they require analysis and negotiation engaging both state and national levels of policy-making. Our concern, rather, is to be certain that all key issues are on the table and to identify ways of addressing them within present constraints.

Overall, the effects of these accumulating pressures have been dispiriting for the healthcare workforce at all levels, from technicians and aides to nurses and physicians. Under such strains, relations between managers and workers providing care are uneasy, ranging from determined efforts to maintain respectful cooperation to adversarial negotiation of grievances, and in several recent instances, to long nurses' strikes against hospitals over contract terms. In general, our interviewees reported an industry under great stress, with debates in many areas concerning specific causes.

\section{Key Workforce and Industry Performance Issues}

The health care industry leaders we have interviewed have been strikingly consistent in identifying the most difficult challenges to the health care industry and its workforce. The basic one, of course, for hospitals and nursing homes, is constant 24 hour a day operation, which requires staffing on nights and weekends as well as traditional work hours. Within this context a number of problems appear to be especially serious.

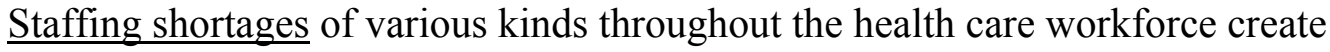
problems for managers and workers and also for the quality of patient care. One result is 
long work hours and inflexible schedules placing pressure on virtually every part of the healthcare workforce, including physicians.

Interviewees also report a generalized problem of degraded and unsupportive working conditions. A dual process of "deskilling" and "speed up" is working to undercut previously understood modes of clinical practice. For example, in hospitals, the time for "soft" tasks such as talking with patients to build trust or helping them manage their anxieties evaporates, and in clinics time to build knowledge of a patient as a whole person is reduced. The result for many is discouragement about their ability to use the full range of their caring skills.

A further set of problems that affects all sectors of the workforce in various ways involves a lack of opportunities for training and advancement in an industry in which occupational categories and terms of work are in a constant state of flux. It is hard to know what kind of training will be needed, supported, and respected for what kind of position, in what health care sector. A related problem concerns professional and employee voice as the industry undergoes rapid reorganization through mergers of hospitals and clinics, and closures of nursing homes. Who gets a seat at the table when hospitals are bought and sold, when workers are laid off, when jobs are reorganized? We have heard a range of views as to whether traditional professional associations can serve the needs of physicians and nurses in this context and whether unions or other forms of representation are most useful for professional and/or non-professional workers.

Although these concerns cut across all the health care occupations, they show themselves differently in each. The following examples highlight problems that seem especially pressing in the different workforce sectors.

\section{$\underline{\text { Issues for Nurses }}$}

- Nurses object to the loss of the professional practice model - the assignment of some bedside tasks to aides who lack knowledge necessary to evaluate patients' conditions - and to the speed-up of tasks reducing time with patients. These are particular concerns as patients are now admitted to hospitals only with serious conditions and the average length of stay is reduced so that more must be done in a shorter time.

- Nurses are also concerned about an accompanying lack of respect for their knowledge and experience, and little opportunity for collaboration with physicians. Increasing numbers of nurses are joining specialty professional organizations through which they can enhance their clinical practice and seek greater professional voice. 
- Staffing shortages are most severe in nursing, affecting acute care teaching and community hospitals, nursing homes, and to some extent, home-based health services.

- There is disagreement about whether the shortage of nurses is due to literal lack of numbers in the state or to problems of recruitment and retention due to difficult working conditions.

- Mandatory overtime, imposed to make up for staff shortages, has been a serious issue for nurses, the basis for several strikes against hospitals, and a central subject in contract negotiations.

- Nurse managers in hospitals are in short supply and are under great pressure to negotiate the often conflicting needs of higher level administrators, nurses, aides, technicians, and patients. Their role as clinicians is often overshadowed by their managerial responsibilities.

- Nurses object to inflexible shifts, too many changes in rotations, pressures to work extra shifts to relieve fellow nurses who are sick, pressures not to call in sick, and pressures to work while sick. They also face pressures not to work, and thus to lose payment, when the patient census is low.

- Nursing school enrollments, while showing a slight recent increase, are too low to meet present and future needs. Most members of the current nursing force are in their $40 \mathrm{~s}$ and $50 \mathrm{~s}$ and will be retiring in the next 15-20 years. Career ladders by which certified nursing assistants (CNAs) could become licensed practical nurses (LPNs) and then registered nurses (RNs) are difficult to negotiate. Workers at lower levels can rarely give up wages for the time additional training would take. Public or other funding to support the needed time and tuition are presently insufficient, and many LPN programs have been cut, removing the bridge from CNA to RN.

- The Massachusetts Nurses Association terminated its membership in the national American Nurses Association in order to follow a course of stronger union advocacy for the particular professional and economic needs of nurses. Following this development, the Mass RN Association was established for those nurses wishing to maintain membership in the ANA. These moves involved confusion and controversy over the identity of nurses as professionals, and how their interests can be best represented and how their concerns for patient care can best be voiced.

\section{$\underline{\text { Issues for Physicians }}$}

- The overriding issue for many physicians is loss of professional voice, autonomy, and control in an industry organized by new systems of health care delivery and cost controls. Whether as employees of large health care providers, or as members of small groups under contract with HMOs, they are increasingly subjected to managed care rules, guidelines, incentives, and monitoring. They have less control over their time, less time with patients, and more scrutiny over what medications to prescribe, what treatments to follow, and whether to admit a patient to a hospital. These functions require heavy loads of paperwork. 
- In hospitals, interns and residents continue to be required to work long hours, often 60-80 a week, and under difficult conditions. Cutbacks in nursing and other staffs have in some cases also adversely affected their workload. They must deal also deal with exhaustion and compromised personal or family life, as well as struggles to provide good patient care.

- Heavy schedules and compromises in private lives often continue beyond early career stages. Reduced reimbursement rates and income levels often require increased working hours, as does training necessary for evolving specialty areas.

- Shortages of physicians have developed in certain specialties with rapidly changing technologies, such as radiology. There are also shortages of physicians with management training important to the running of large medical groups and hospitals. This seems to be due both to lack of physician interest in management and to the time and money needed for education in a second field.

- Representation of the professional needs and interests of physicians is in question in the changing field of health care. Previously, the American Medical Association (AMA) and state medical societies held monopolies on representation; now however, $80 \%$ of physicians belong to one of the many specialty associations, and AMA membership has declined to $40 \%$. These specialty associations control board certification and clinical guidelines in their fields.

\section{$\underline{\text { Issues for Technicians, Aides, and Entry-Level Workers }}$}

- There are shortages of technicians in a number of fields, including pharmacology, radiology, and respiratory therapy. There are also staff shortages of health aides in hospitals, assisted living centers, home health services, and most severely in nursing homes. In some nursing homes, the turnover rate of aides is $100 \%$.

- The related issues of shortage and turnover are due to low wages in difficult or unpleasant work environments. These workers who live at or near the poverty level who must often take two or three jobs to make ends meet and have no resources for dependent care or higher levels of education.

- There is a general problem with hours and schedules for entry-level hospital workers in departments, such as surgical units and emergency rooms, which run on a 24/7 basis. The need for workers to do evening, weekend, and rotating shifts causes significant problems for child care, transportation, education, and training.

- Access to training and effective career ladders is a serious problem for entry-level, semi-skilled workers in housekeeping, food services, building maintenance, transportation, and nursing assistance. Time for training is rarely supported financially and low-paid workers cannot afford to lose work time and wages. Also, in some workplaces, managers resist releasing workers from their jobs for classes.

- Another issue in entry-level work is racial and ethnic disparity as many people in this sector of the workforce are immigrants or American minorities. 


\section{Implications for Connections between Work and Family}

Many people interviewed initially stated that work-family issues are not really a pressing matter for the health care workforce. But they then went on to list many issues that directly and indirectly are clearly part of the work-family domain and have clear multidimensional impacts. We see the invisibility of these issues as an issue in itself. Certainly for the individual worker, work and family are not two separate subjects. Rather, they form a continuum in which trouble and stress at any point along the way affects the whole.

Lack of sufficient attention to this continuum is, of course, a problem throughout the society given the long-standing belief that family responsibilities are private concerns. But it appears that in health care workplaces, a paramount ethic of patient care further removes the needs of workers' families as a matter to be considered in the organization of work. As physicians, nurses and other workers deal with issues of life and death, they can feel selfish - as many say they do--asking for attention to the ordinary, daily matters of family life. But many also say they feel that their concern for patients is exploited by administrators organizing staff levels and schedules that create severe pressures for families.

Overall, the interviews reveal that people in all parts of the workforce who seem on the surface to have little in common - for example, physicians and nurses aides - do have in common a great deal of trouble integrating work and family in a satisfactory way.

The relative invisibility of work-family issues is a particular problem for the health care workforce because it includes a large percentage of women and it is usually women who assume primary responsibility for family care. For women physicians the problem is exacerbated by the fact that they have moved into a profession traditionally dominated by men whose identity centered heavily on work. Time for families and direct responsibility for their day to day care were not built into conceptions of physicians' days, their career tracks, or their requirements for advancement. But many women, who now make up half of medical school classes, seek to include childbirth and time for families in their lives, and work-family conflicts for them become severe. However, the clarity of their issues has had the further effect of raising them for the increasing numbers of male physicians who want to spend time with families. As in other professions, the entry of women in significant numbers has brought with it the larger question of taking account of families in the organization of work. 
In general, we see the connection between workers' problems with family care and employers' problems with patient care to be insufficiently explored and documented. And yet they seem intrinsically interwoven. The very same things seen as workplace problems that compromise patient care also create family problems for employees at all levels. We give examples below.

\section{Staffing}

In hospitals, staff shortages increase individual work loads in all divisions of the workforce; they put pressures on nurses to work extra shifts; and exhausted workers have diminished physical and emotional reserves left for families.

Insufficient numbers of workers also contributes to workforce injuries-for example, when one nurse or aide is responsible for lifting or turning heavy patients. Such injuries result in sick leaves that may strain family finances and the capacity of families to take care of the injured worker.

\section{Time Pressures: Un-family-friendly Hours and Schedules}

Mandatory overtime and otherwise inflexible schedules cause problems for any employee with responsibility for family care. Little time may be allowed to make arrangements for picking up a pre-school child, or to provide supervision for older children, or for an elder's special needs.

Interns and residents follow the traditional pattern of work weeks running to 60 hours or more, which compromises starting or sustaining a family and creates particular difficulty for women who typically reach this stage during prime child-bearing years.

Stressed workers do not have time to participate, to volunteer, or even to go to community events, not only because of long work hours but also because of long commutes. The personal and social costs of lost connections to community are hard to calculate, but one result of these losses is a reduction of a variety of family supports that depend on cooperative volunteer efforts.

Older experienced nurses are extremely valuable in the practice environment as clinicians, trainers and mentors. However at this stage, they also face increased family needs as they seek to give time to retiring husbands, adult children with young children of their own, and elderly parents. 


\section{Degraded Working Conditions}

Displeasing conditions at work often produce resentments or even depression that may carry over into tensions at home. Also, dispiriting working conditions may enter a worker's general calculation about the worth of staying in a pressured, unenjoyable job. If problems with schedules and exhausting demands create difficulties for families, factors such as lack of respect or constraints on relational care may convince a worker to seek other employment.

\section{Lack of Opportunity}

Low wages for semi-skilled workers provide little money for child care, or other family needs, and low to middle income workers, especially single parents, have great difficulty sacrificing work time and wages for training necessary for higher paying jobs.

\section{$\underline{\text { Loss of Voice }}$}

When health care workers are effectively excluded from the processes of reorganization and consolidation now occurring in the industry, they may feel devalued at work and this may have a negative spillover effect on family life. In addition, workers may feel further frustrated because of the difficulty of voicing their concern about the impact of industry-wide changes on their families.

As is evident, these problems then feed back to exacerbate and reinforce the very conditions that initially caused them. Though seemingly intractable, this negative reinforcement does open up the possibility that by experimenting with changes that ease employees' lives, one might at the same time enhance patient care. We suggest some possible ways to think about this at the end of this report but turn, first, to the industry response to some of these issues. 


\section{The Health Care Industry Response}

The employers and organizations we have talked to thus far are making a number of efforts to address the issues and challenges described above.

\section{$\underline{\text { Individual Institutional Responses }}$}

In the area of staffing, many hospitals have created in-house positions for "nurse recruiters" whose full time job it is to fill nursing vacancies and develop strategies for retaining the nurses already on staff. Other hospitals and other types of service providers use private nurse recruiting firms that provide nurse temps and work with employers to recruit permanent staff nurses. It is not uncommon to hear about signing bonuses, waiving years of service requirements for new RNs, and establishing very competitive wage and salary scales for nurses and nurse managers.

In terms of problems with hours and schedules, part-time and flexible hour arrangements are available in many settings. Some nurses work on a "weekends only" schedule, others have worked out "full-time" schedules built around three 12 hour days. Part-time options are now available to physicians in certain specialties and types of group practice. How successful these alternative work schedules are seems to vary and may be undercut by the demands of mandatory overtime, the general problem of staffing shortages, the limits of effectively handing-off patients between caregivers, and the "on call" system for doctors.

There are a variety of ways that institutions are responding to difficult or degraded working conditions. Some institutions that include low-paid aides in their workforce and do not have the resources to increase wages, have instituted programs to generate a culture of respect for staff at this level. They conduct staff surveys about work satisfaction and talk individually to staff members to find out what people need so that they can make accommodations where possible. One hospital has also organized a "Respect Campaign" that was conceived and implemented by a team of professional and non-professional employees. Another provider has a "Spirituality in the Workplace" program to bring non-traditional resources to staff dealing with high levels of stress and fatigue. 
Training and career ladders for low-income workers are supported in some institutions through tuition payments for courses, collaboration with community colleges and other training sites to develop needed courses, and occasionally, the offering of courses on-site, especially for English language training. The Commonwealth Corporation and the Paraprofessional Healthcare Institute, with a grant from the state legislature, are presently organizing training programs in nursing homes.

The question of enhancing professional and employee voice is essentially unsettled in a period of continuing institutional restructuring, although some groups have organized effectively. The Massachusetts Nursing Association employs collective bargaining and legislative campaigns to promote nurses' concerns. Other groups, including interns and physicians, are also seeking ways to pursue issues collectively whether through unions or other means.

Some interviewees tell us that there is a growing interest in the health care industry in "Total Quality Management” (TQM) as an approach that could potentially address a number of the workforce issues described above. Others raise concerns about the disappointing results of TQM in other industries as a "stand alone" technique without supporting employment and human resource practices.

Work-family issues have received less attention than most other workforce issues. While some employers have established "family-friendly" benefits, such as child care resource and referral services, a sustained set of initiatives exists in only a limited number of large organizations. For example, one large hospital has merged its work-family programs and resources under its Employee Assistance Program and has created a backup child care center for employees and patients. Most major urban hospitals have reserved limited slots in on-site child care centers, but this is an option for only a fraction of their workforce. One is currently closing its child care center, leaving over 140 families to make new arrangements. So even in some of the workplaces that have been most accommodating to families, there seems to be little growth in these benefits due to the need to control costs overall. Those who work in nursing homes, home-health agencies, and assisted living centers lack this kind of support with child care and/or elder care. 


\section{$\underline{\text { Cross-Sector Responses }}$}

There are a number of health care organizations that have formed ad hoc coalitions to jointly lobby state and federal agencies and legislators for increased health care reimbursements and other supports, such as financing for nurse training. MNA is filing a bill to promote "safe staffing" levels. While these coalitions may be short lived, they often bring together a broad cross-section of professional and non-professional health care workers with consumers and community groups.

The State legislature has addressed a number of workforce issues. For example, it has provided funds to increase compensation and benefits for CNAs in nursing homes and to expand their training opportunities. It has established staffing ratios for long term care facilities and bills are under consideration to increase higher Medicaid reimbursement for nursing homes. An act establishing a Commission on Long Term Care has passed both houses with an initial two-year mandate. It is beyond the scope of this paper to summarize all pending legislation, but bills such as the proposed paid parental leave bills would positively impact the state's many low wage health care workers.

Some groups have come together to gather better data. An example of this is the Center for the Heath Care Professions at Worcester State College. With support from state funding, the Center brought together nurse executives, nursing unions, nursing schools, and the nurse licensing board to design a survey on the nursing workforce in the state. (Survey results are due this fall.) There is also a new state funded survey of the health care workforce being run by Boston's Private Industry Council.

The largest cross-sector effort on health care to date is the Governor's Health Care Task Force. Formed early in 2000, the Task Force is comprised of 50 members. They include the elected bipartisan leadership of the state, leaders of the major teaching hospitals and other service providers, insurers, industry trade associations, industry labor unions, health care professional associations, and academic researchers. Its mandate was one of fact-finding, defining problems, and setting out for consideration a range of possible solutions. Through a process of public hearings and open Task Force meetings, the Task Force has produced an interim report based on the efforts of four working groups. These groups have studied financial issues, health care quality, access, and administrative simplification.

Although the Task Force is impressive in its attempt to bring together major stakeholders in the health care industry, they have yet to address issues affecting the 
health care workforce. Their intent to focus on physicians, nurses, and other direct care workers appears on a list of fourteen issues for the future. The domain of "work and family" issues is not named for consideration. This is a void that we hope the MIT Workplace Center in collaboration with others might begin to fill.

\section{Next Steps: Leverage Points for Experimental Change}

The large question that we see arising from present pressures within the health care industry is: what kinds of change in the systems now in place-in workplaces, in government, in community services, in families, in other related venues--would support improvements in both patient care and family care? Our working assumption is that troubles at work cause troubles at home, and vice versa, so that interventions at any point in connections among workers, their jobs, and communities might be expected to affect the other parts of the whole. Our aim, therefore, is twofold:

- to document the relationship between troubles at work and troubles at home; and

- to locate points in these connections where interventions of some kind could produce multiple benefits.

As a way to start thinking about both documentation and intervention, we would like to propose several ideas for group discussion.

\section{$\underline{\text { Research on Family Impacts }}$}

Underlying most work-family problems, not only in health care but throughout the society, is a deeply-rooted system of beliefs that defines the family as a private entity operating in a sphere apart from public and work life, and responsible for its own support and welfare. In health care, the central value of patient care further eclipses the needs of workers' families as a prominent concern both for employers and workers.

- We propose to make these "private" impacts more "public" by documenting the way stresses and pressures in the healthcare workplace affect workers' families and the way family pressures affect workers' ability to provide top level patient care.

Would you be interested in participating in an Advisory Group to assist us in designing a project - across institutions and occupations - documenting the relationship between work and family in the health care industry? 


\section{$\underline{\text { Workplace-based Interventions }}$}

All of the workforce issues outlined above are interrelated in various complex ways. Staffing shortages and inflexible hours and schedules are integrally connected to each other. Both are crucial to the quality of working conditions. Changes in any of these areas raise questions about the importance of employee voice. In designing interventions addressing work and family problems, it will be important to take these interconnections into account. We have attempted to do so in the following suggestions and seek your advice about their workability.

- We are aware that cross-functional teams that bring together staff with different levels of status, training, and skill have been tried in various health care settings. Some say they are welcomed as promoting communication, efficiency, and respect for varying contributions. Others say they are resisted as wasting time and undermining the authority of team members - physicians, nurses — with superior knowledge.

\section{What has been learned from past experience with such teams? Would the value of cross-functional teams be a useful focus for study and potential change?}

- Staffing problems are endemic in hospitals and nursing homes. Health care workers at all levels in institutions that operate on a 24/7 basis are plagued with difficult schedules and shift options.

\section{Do you think a collaborative work redesign effort could effectively address the interconnected issues of staffing, scheduling and work organization? What alternative forms of work organization might relieve present pressures?}

- Middle management positions are a place where current tensions in the health care delivery system seem to be especially severe. For example, the position of nurse manager is under siege from administration above and staff below. We have heard that workers in these positions work long and sometimes irregular hours, that they may not be paid much more than the nursing staff, that their numbers have been cut, and that there is currently a shortage. Recruitment is difficult because the pressures of the position are not well supported. 
Does this function call for close examination and possible redesign? What new systems of support could improve the ability of workers at this level to meet the needs of their multiple responsibilities?

- Community supports for health care workers with non-traditional schedules can be particularly important — for example, transportation and child care services operating in late evening and nighttime hours.

How can firm, on-going relationships between health care workplaces and community services be established and supported to better recognize the needs of workers with non-traditional hours and other scheduling problems?

- Employee voice is important for creating the conditions that will allow people to enhance patient care without sacrificing the well being of their families or themselves.

What new or reorganized systems could improve the ways in which the various categories of workers express their ideas and concerns?

- A number of nurses and physicians have spoken about the importance of the clinician voice in the administration of hospitals and medical groups, while acknowledging the reluctance of many clinicians to go into management.

How serious a problem is the present lack of clinician leadership? Given past experience and present needs, what initiatives to develop such leadership might be undertaken? 


\section{Next Steps - Continued Engagement}

We could not, of course, undertake to act on more than a few interventions in the course of the Center's work in health care. We seek advice about these questions:

Which of the projects described above, if any, seem especially promising?

What other possibilities for change do you see?

What has been your previous experience with redesigns that have worked well or badly?

Would you be interested in working on any of these or other initiatives in your workplace? 


\section{ACKNOWLEDGEMENTS}

\section{We would like to thank the following individuals who contributed their time and expertise to the preparation of this working paper. We apologize for any omissions in titles or credentials, and request that you give us the correct information by email for our permanent records. (workplacecenter@mit.edu)}

Laura Avakian, Vice President, Human Resources Massachusetts Institute of Technology (formerly Vice President, Human Resources, Beth Israel Deaconess Medical Center)

Carolyn R. Blanks, Vice President, Labor and Workforce Development Massachusetts Extended Care Federation

Phil Boulter, MD, COO

Tufts Health Plan

Robert Buxbaum, MD

Harvard Vanguard Medical Associates

Kathleen Casavant, Secretary-Treasurer

Massachusetts AFL-CIO

Eloise Cathcart, Ph.D., R.N., Director, Policy and Program Collaborative

Institute for Nursing Health Care Leadership

Senator Harriette L. Chandler

Massachusetts General Court

John Chessare, MD, MPH, Sr. VP, Medical Affairs, Chief Medical Officer, Boston Medical Center

Joyce Clifford, Ph.D., R.N., Executive Director Institute for Nursing Health Care Leadership

Nancy DePaul, Director, Human Resources, Lemuel Shattuck Hospital

Martha Pyle Farrell, Director, Operational Planning and Program Improvement

Brigham and Women's Hospital
Roslyn Feldberg, Research Director Massachusetts Nurses Association

Barbara Frank

Paraprofessional Health Care Institute

Louis I. Freedman, Commissioner

Division of Health Care Finance and Policy,

Commonwealth of Massachusetts

John Fromson, MD, Vice President

for Professional Development

Massachusetts Medical Society

Joanne Handy, CEO

Visiting Nurses Association of Boston

Robert Haynes, President

Massachusetts AFL-CIO

Valerie Hunt, Ph.D., R.N., Vice President for Patient Services

St. Elizabeth's Hospital

Hikaru (Carl) Isihara, MD, Trustee, Physicians'

Council, Harvard Vanguard Medical Associates

Annette Jacobs, Executive Director MIT Medical

Michael Kane, MD, Medical Director

Longwood Mariner's Extended Care Facility

Nancy Kruger, DNSc, R.N.

Vice President for Patient Services

Brigham and Women's Hospital 
Richard Lane, MD

Harvard Vanguard Medical Associates

Virginia Latham, MD, Past President

Massachusetts Medical Society

Barbara Munro, Ph.D.,

Dean

Boston College School of Nursing

Carol Nadelson, MD, Director, Office of Women's Careers

Brigham and Women's Hospital

Julie Pinkham, Executive Director

Mass Nurses Association

Scott Plumb, President

Massachusetts Extended Care Federation

Brad Prenney, Deputy Director,

Health Policy Management

Department of Public Health

Allison Caplan Rimm, Vice President

for External Affairs

Massachusetts General Hospital

Maria Roloff, Vice-President for Human Resources

Cambridge Health Alliance

Luis Sanchez, MD, Director, Physician Health Services

Massachusetts Medical Society
Representative Harriett Stanley

Massachusetts General Court

Robert L. Shafner, Executive Director

Center for the Health Professions

Barry Small, Practice Manager, Kenmore Center Harvard Vanguard Medical Associates

Andrea Stidsen, Director, Employee Assistance Programs

Massachusetts General Hospital

Bonnie Tavares, Director, Office of Employee Programs

Department of Public Health

Joan Vitello, Ph.D., R.N., Director, Leadership, Development and Assessment Collaborative Institute for Nursing Health Care Leadership

Patricia Webb, Vice President for HR Boston Medical Center

Martha Weinberg, former Senior Administrator Mass General Hospital and Partners Health Care

Celia Wcislo, President

Service Employees International Union, Local 285

James Wessler, Executive Director

Massachusetts Alzheimer's Association

In addition, we would also like to thank the Massachusetts Nurses Association and the Visiting Nurses Association of Boston for their assistance in convening focus groups of their members and staff. To those health care employees who participated in these conversations, we also extend our appreciation for sharing their work and family experiences. 


\section{Other Publications from the MIT Workplace Center}

Enhancing Patient Care Through Enhancing Employee Voice: Reflections on the Scanlon Plan at Boston's Beth Israel Medical Center,

Mitchell T. Rabkin, MD and Laura Avakian (\#WPC0002)

An Employment Policy Agenda for Working Families,

Thomas A. Kochan (\#WPC0003)

Work Redesign: Theory, Practice, and Possibility,

Lotte Bailyn and Joyce K. Fletcher (\#WPC\#0004)

Keeping Caring Caregivers: Policy and Practice Initiatives in Long Term Care

Susan C. Eaton and Barbara Frank (\#WPC0005) 